\title{
||||||||||||||||||||||||||||||||||||||||||||||||||||||||||||||||||.
}

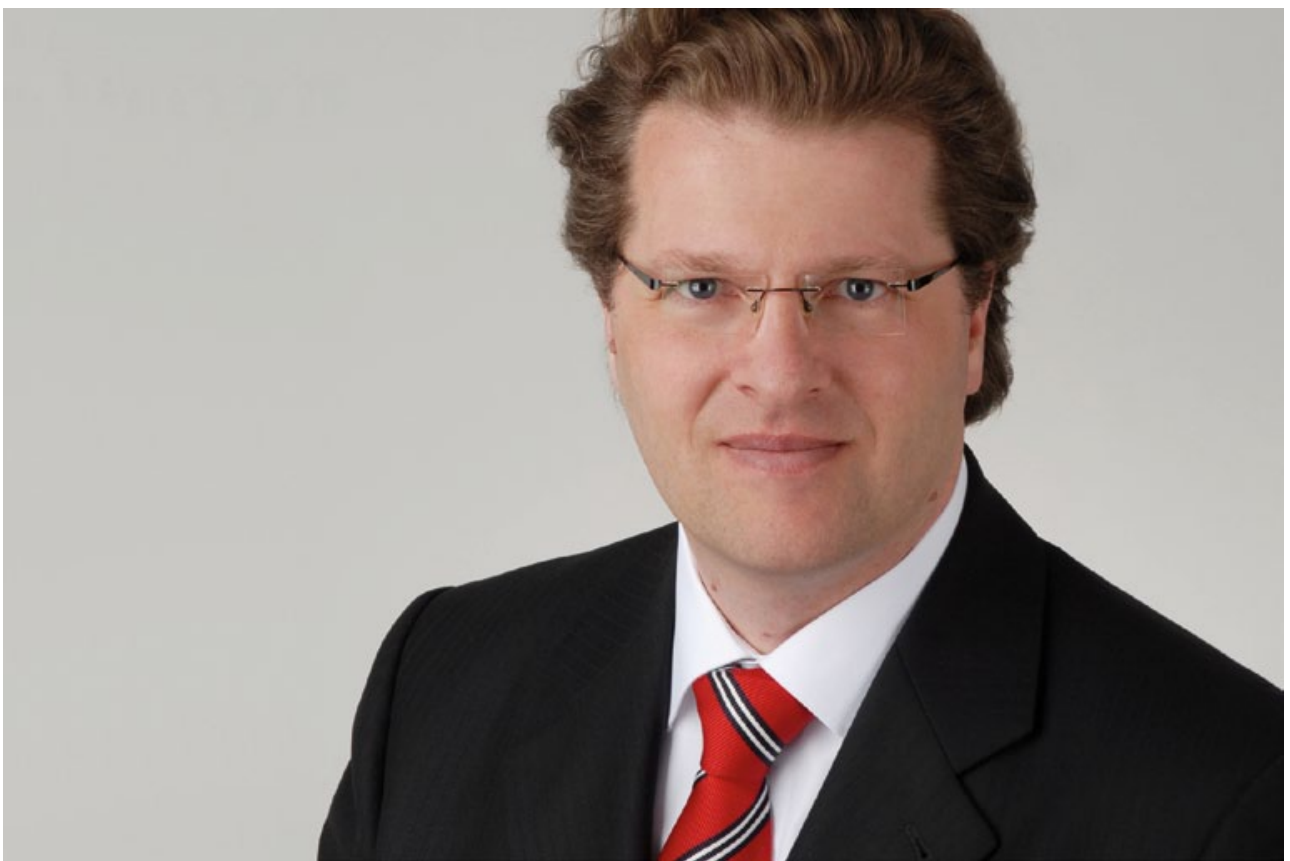

PROF. DR.-ING. LUTZ ECKSTEIN

Leiter des Instituts für

Kraftfahrzeuge (ika),

RWTH Aachen University

\section{MIT SICHERHEIT ELEKTROMOBILITÄT}

Globalisierung und Urbanisierung, Ressourcenverknappung und Klimawandel bei gleichzeitig schwierigen wirtschaftlichen Rahmenbedingungen stellen die gesamte automobile Wissenschaft und Wirtschaft vor gewaltige Herausforderungen. Diese Herausforderungen zu meistern, erfordert, neue Wege zu gehen - nicht nur technisch, sondern auch akademisch und strategisch.

Technisch: In der aktuellen Diskussion kommt das Thema Sicherheit viel zu kurz - sei es, weil wir Sicherheit als selbstverständlich voraussetzen oder weil Sicherheit als Thema durch die Elektromobilität verdrängt wird. Dabei spielt die Sicherheit gerade bei der Einführung der Elektromobilität eine entscheidende Rolle: Während wir uns an die Risiken des Transports und der Verbrennung fossiler Kraftstoffe gewöhnt haben, reagiert unsere Gesellschaft sehr sensibel auf Risiken „neuer“ Technologien wie etwa der Hochvoltbatterie. Umso wichtiger ist es, innovative Ansätze und Konzepte zu erforschen und diese sowohl auf System- als auch auf Gesamtfahrzeugebene systematisch und umfassend abzusichern. Wir müssen zwingend vermeiden, das Zukunftsthema Elektromobilität sprichwörtlich „zu verbrennen“. Dabei geht es längst nicht mehr nur um die passive Sicherheit - auch die elektrische Sicherheit, die funktionale Sicherheit und die Datensicherheit sind zentrale Dimensionen des Vektors Sicherheit.

Akademisch: Das Automobil ist mit Sicherheit in den vergangenen Jahren zu einem der komplexesten Massenprodukte überhaupt geworden und bewegt sich zudem in einem immer komplexer werdenden Umfeld - sowohl hinsichtlich des Ver- kehrs als auch hinsichtlich der Vernetzung von Mensch und Technik. Die erfolgreiche Gestaltung der nachhaltigen Mobilität von morgen erfordert das Zusammenwirken zahlreicher Disziplinen, vom Maschinenbau über die Elektrotechnik und Informatik bis hin zur Psychologie und dem Design - einen Weg, den wir am Institut für Kraftfahrzeuge (ika) der RWTH Aachen University systematisch verfolgen. Denn die Transformation von E-Mobilität in E-Motion gelingt uns mit Sicherheit nicht, solange wir eine primär technische Diskussion führen. Ich möchte deshalb Studierende aller Disziplinen ermutigen, das Kraftfahrzeug der Zukunft aktiv mitzugestalten.

Strategisch: Auch Skeptiker werden akzeptieren, dass die Elektromobilität mit Sicherheit kommen wird. Ganze Wirtschaftsräume haben faktisch keine andere Möglichkeit, individuelle Mobilität volkswirtschaftlich und sozial verträglich zu realisieren, als auf einen signifikanten Anteil (vorwiegend) elektrisch angetriebener Fahrzeuge zu setzen, wobei Zweiräder und Kleinstfahrzeuge eine große Rolle spielen werden. Auch in Europa werden wir in wenigen Jahren einen Wettlauf von Städten und Ballungszentren um den Ruf der saubersten und lebenswertesten Metropole erleben, der die Verbreitung der Elektromobilität vorantreibt - sofern wir diese gemeinsam sicher ausgestalten.

Um die skizzierten Handlungsfelder mit Ihnen eingehend zu diskutieren, würde es mich sehr freuen, Sie am 7. Oktober 2013 zum 22. Aachener Kolloquium Fahrzeug- und Motorentechnik begrüßen zu dürfen. 